\title{
COMENTARIO MONOGRÁFICO
}

\section{EL DISCUTIDO CÁLCULO DE LAS MULTAS EN MATERIA DE DEFENSA DE LA COMPETENCIA}

\author{
Miguel Casino Rubio \\ Universidad Carlos III de Madrid
}

\begin{abstract}
RESUMEN
La STS de 29 de enero de 2015, a la que luego han seguido simplemente otras muchas, ha echado por tierra la Comunicación que la Comisión Nacional de los Mercados y la Competencia (CNMC) publicó en febrero de 2009 detallando el método a seguir para calcular el importe final de las multas que impone por las infracciones previstas en la Ley 15/2007, de Defensa de la Competencia. EI presente trabajo repasa la citada sentencia y alerta de alguna de sus debilidades.
\end{abstract}

Palabras clave: proporcionalidad y motivación del quantum de las sanciones; control judicial; soft law.

\begin{abstract}
Spanish Supreme Court decision of 29th J anuary 2015 withdrew the Communication on fine setting published by the Spanish Competition Authority in February 2009 detailing the method to calculate the final amount of the fines imposed for infringements provided for in the Competition law 15/2007. This paper reviews the aforementioned sentence and aware us of its weaknesses.
\end{abstract}

Keywords: fines in antitrust; proportionality; soft law. 


\section{SUMARIO}

I. Planteamiento.- - II. Los términos de la controversia.-lil. La Sentencia de la Audiencia Nacional de 6 de marzo de 2013.-IV. La Sentencia del Tribunal Supremo de 29 de enero de 2015.-V. Observaciones finales.

\section{Planteamiento}

La STS de 29 de enero de 2015, a la que luego han seguido simplemente otras muchas (últimamente, entre otras, SSTS de 11,28 y 30 de septiembre, y 2 de octubre de 2015), ha puesto fin por el momento a la discrepancia de criterio que mantenían la Audiencia Nacional y la Comisión Nacional de los Mercados y de la Competencia (CNMC) sobre la interpretación que mejor conviene al art. 63.1 c) de la Ley 15/2007, de 3 de julio, de Defensa de la competencia (LDC).

La disputa se remonta a la primavera de 2013, cuando la Sala de lo Contencioso-Administrativo, en una larga serie de sentencias que arranca con la dictada el 6 de marzo de 2013 (asunto Vinos Finos de Jerez), decidió corregir el criterio que desde 2009 utilizaba la CNMC para calcular el importe de la multa correspondiente a las infracciones a la LDC.

Para comprender mejor los motivos de esa controversia conviene recordar ahora sus principales episodios.

\section{LOS TÉRMINOS DE LA CONTROVERSIA}

El art. 63.1 LDC establece que las infracciones que tipifica la propia Ley podrán ser corregidas, según sean calificadas de leves, graves o muy graves, con multa respectivamente de hasta el 1, el 5 y el $10 \%$ del volumen de negocios total (VNT) de la empresa infractora en el ejercicio inmediatamente anterior al de imposición de la multa. La LDC no señala, por tanto, para cada infracción que tipifica una sanción fija y automática, sino que previene simplemente una franja u horquilla sancionadora (formulada en este caso mediante la expresión de un margen máximo), confiando la decisión de determinar el quantum de la sanción a la propia Administración, con sujeción a los criterios de graduación que la propia LDC se encarga de precisar en el siguiente art. 64 .

Esta forma de tipificar las sanciones es absolutamente frecuente en nuestro ordenamiento y, de hecho, son contadas las Leyes sancionadoras quefijan con precisión la sanción que automáticamente corresponde 
a cada una de las infracciones que tipifica. Pero también, y lo que ahora es más importante, jurídicamente irreprochable, según lo confirma la doctrina del Tribunal Constitucional que nunca ha advertido ninguna tacha de tipicidad en cualquiera de las abundantes Leyes sancionadoras que remiten a la decisión de la Administración la determinación de la concreta sanción aplicable a la infracción detectada. Conforme en fecha más reciente han subrayado las SSTC 175/2012, de 15 de octubre (FJ 3), y 145/2013, de 11 de julio (FJ 8), «resulta compatible con la garantía del principio de legalidad sancionadora que el legislador atribuya discre cionalidad a la Administración dentro de unos límites para concretar el alcance o importe de la sanción».

De todas formas, que esa fórmula de tipificación de las sanciones no sea irregular no significa naturalmente que no sea controvertida. De hecho, según suele advertirse ${ }^{1}$ y es fácil de comprobar por otra parte con sólo repasar la jurisprudencia contenciosa, la previsión por la Ley de criterios de graduación termina en ocasiones por apretar más bien poco a la Administración encargada de aplicarlos, de modo que no consigue reducir significativamente el arbitrio del órgano sancionador, cuya decisión final sobre el quantum o extensión de la sanción acaba siendo por lo mismo muchas veces cuestionada por desmedida, según lo confirma la jurisprudencia contenciosa que está, en efecto, repleta de sentencias que abordan ese tipo de impugnaciones.

Probablemente por esta razón y, en cualquier caso, con el confesado propósito de guiar su actuación y «contribuir a mejorar la transparencia y la objetividad en el cálculo de la correspondiente sanción, potenciar su efecto disuasorio y favorecer la seguridad jurídica de los operadores económicos», Ia CNMC publicó en febrero de 2009 una Comunicación detallando el método a seguir para calcular el importe final de la multa a imponer en cada caso, y que descompone en tres fases².

La primera fase se corresponde con la determinación del denominado «importe básico de la sanción», que consiste en un porcentaje sobre el volumen de ventas afectado por la infracción, calculado siguiendo los criterios de graduación previstos en las letras a) a e) del art. 64.1 LDC³.

1 M. Rebollo Puig et al. (2010), Derecho Administrativo Sancionador, Lex Nova, Valladolid, p. 827.

2 Comunicación de 6 de febrero de 2009, de la CNMC, sobre la cuantificación de las sanciones derivadas de infracciones de los arts. 1, 2 y 3 de la Ley 15/2007, de 3 de julio de Defensa de la Competencia, y de los arts. 81 y 82 del Tratado de la Comunidad Europea, BOE núm. 36, de 11 de febrero de 2009.

3 El citado art. 64.1 LDC, bajo la rúbrica de «criterios para la determinación del importe de las sanciones» establece que el importe de las sanciones se fijará atendiendo, entre otros, a los siguientes criterios: a) La dimensión y características del mercado afectado por la infracción; b) La cuota de mercado de la empresa o empresas responsables; c) El alcance de la infracción; 
Este importe básico, que parte del $10 \%$ del volumen de ventas afectado por la infracción, puede incrementarse en otro $10 \%$, en el caso de las infracciones muy graves, y puede todavía hacerlo hasta en un $10 \%$ más $y$, por tanto, alcanzar finalmente el $30 \%$ del volumen de ventas afectado por la infracción, cuando además el mercado o mercados afectados correspondan a un input productivo susceptible de provocar efectos en cascada en otros mercados distintos al considerado en el expediente.

El resultado de ese importe básico se incrementa o reduce luego, en una segunda fase, en función, según sea, de las concretas circunstancias agravantes o atenuantes en cada caso concurrentes, de entre las previstas respectivamente en los apartados 2 y 3 del art. 64 LDC $^{4}$, en una proporción o coeficiente de ajuste que varía igualmente entre un 5 y un 15\% del importe básico por la apreciación de cada una de esas circunstancias modificativas.

Finalmente, en la tercera fase, se establecen dos precisiones finales. De un lado, y para el caso de que en el expediente haya sido posible calcular el beneficio obtenido con la infracción, la Comunicación advierte que el importe de la multa obtenido en aplicación de los criterios anteriores no podrá ser inferior al citado beneficio ilícito. Y deja claro igualmente que el importe final de la sanción no podrá nunca superar los límites máximos que, para cada tipo de infracción, previene el art. 63.1 LDC, y que ya conocemos.

Ajustándose escrupulosamente a estos criterios, la CNMC ha dictado, en efecto y desde entonces, con absoluta normalidad no pocas resoluciones sancionadoras, sin recibir en un primer momento ninguna tacha judicial. Hasta que el citado asunto Vinos Finos de J erez llegó a la Sala de lo Contencioso-Administrativo de la Audiencia Nacional.

\footnotetext{
d) La duración de la infracción; e) El efecto de la infracción sobre los derechos y legítimos intereses de los consumidores y usuarios o sobre otros operadores económicos; f) Los beneficios ilícitos obtenidos como consecuencia de la infracción; y g) Las circunstancias agravantes y atenuantes que concurran en relación con cada una de las empresas responsables.

${ }^{4} \mathrm{EI}$ art. 64LDC dispone en su apartado 2 que, «para fijar el importe de las sanciones se tendrán en cuenta, entre otras, las siguientes circunstancias agravantes: a) La comisión repetida de infracciones tipificadas en la presente Ley; b) La posición de responsable o instigador de la infracción; c) La adopción de medidas para imponer o garantizar el cumplimiento de las conductas ilícitas; y d) La falta de colaboración u obstrucción de la labor inspectora, sin perjuicio de la posible consideración como infracción independiente según lo previsto en el artículo 62».

Por su parte, en el siguiente apartado 3 previene con idéntico fin las siguientes circunstancias atenuantes: a) La realización de actuaciones que pongan fin a la infracción. b) La no aplicación efectiva de las conductas prohibidas; c) La realización de actuaciones tendentes a reparar el daño causado; y d) La colaboración activa y efectiva con la Comisión Nacional de la Competencia llevada a cabo fuera de los supuestos de exención y de reducción del importe de la multa regulados en los artículos 65 y 66 de esta Ley.
} 
III. La Sentencia de la Audiencia Nacional de 6 de marzo de 2013

Antes de ver con algo más de razón la opinión de la Audiencia Nacional en el citado asunto, importa notar que, según está reconocido por la propia CNMC, Ia citada Comunicación toma pie, al igual que ya antes lo habían hecho las Directrices (Guidelines) para el cálculo de las multas publicadas en 2006 por la Autoridad alemana de la competencia (Bundeskartellamt), en el art. 23 del Reglamento CE 1/2003, del Consejo, de 16 de diciembre de 2002, relativo a la aplicación de las normas sobre competencia previstas en los arts. 81 y 82 del TUE, y, en especial, en la interpretación del citado precepto defendida por el TJUE, y de la que son buena muestra la sentencia del Tribunal de J usticia (Gran Sala) de 28 de junio de 2005, y más recientemente, las sentencias del Tribunal General, de 12 de diciembre de 2012 y de 14 de mayo de 2014.

Resumiendo ahora mucho las cosas, para el TJ UE el límite del 10\% del importe global del volumen de negocios del que habla el art. 23 del Reglamento no es, en rigor, una multa máxima, ni tampoco una franja sancionadora que forzosamente la Comisión no pueda abandonar en ningún momento. Es, por el contrario, un umbral denivelación que funciona únicamente al final del proceso de determinación de la sanción para, llegado el caso, rebajar el importe de la multa, previamente calculado en función de los correspondientes criterios de graduación (en el caso comunitario, la gravedad y la duración de la infracción), hasta ajustarlo a ese límite legal infranqueable. De modo que, para la jurisprudencia comunitaria, el límite del $10 \%$ no impide que la Comisión, en sus cálculos, eventualmente se aparte de ese límite o utilice criterios de graduación que ocasionalmente arrojen un saldo superior. Lo único que prohíbe es que el importe de la multa impuesta lo supere finalmente.

Teniendo a la vista estas precisiones la Audiencia Nacional observó, en lo que ahora exclusivamente más nos interesa, que la prevalencia del Derecho europeo y esa interpretación de los órganos judiciales comunitarios que se ha dejado anotada sobre el significado del $10 \%$ previsto en el art. 23 del Reglamento 1/2003, no es vinculante, sin embargo, «ni implica su traslado automático a los órganos nacionales de Defensa de la Competencia», una vez advertido, en particular, que el Derecho europeo de la competencia no ha impuesto la uniformidad y supuesta, por tanto, la facultad de los Estados miembros para ordenar conforme a sus propias opciones el régimen sancionador en esta materia. De modo congruente, la interpretación del régimen sancionador previsto en la LDC debe hacerse principalmente con arreglo a los propios principios y 
reglas del Derecho nacional y, en particular, en nuestro caso, a la luz del principio de legalidad sancionadora del art. 25.1 CE.

Sobre el principio de legalidad sancionadora del art. 25.1 CE existe una consolidada doctrina constitucional que está resumida, entre otras muchas, en las SSTC 100/2003, de 2 de junio; 104/2009, de 4 de mayo; y 145/2013, de 11 de julio, y que la propia SAN se encarga seguidamente de recordar, sirviéndose de la primera de esas sentencias constitucionales.

De acuerdo con esta doctrina, el art. 25.1 CE incorpora la regla nullum crimen nulla poena sine lege, y comprende una doble garantía.

La primera, que es de orden material y carácter absoluto, y que deriva «del mandato de taxati vidad o de lex certa», impone la exigencia de predeterminación normativa de las conductas ilícitas y de las sanciones correspondientes, para que los ciudadanos puedan conocer de antemano el ámbito de lo prohibido y prever, de este modo, las consecuencias de sus acciones. De modo congruente, esta exigencia obliga al legislador a definir «con la mayor precisión posible» o «con el mayor esfuerzo posible» $y$, en cual quier caso, «con suficiente grado de certeza» las conductas que constituyen infracción y el tipo y grado de la sanción que le ha de corresponder.

En esa misma jurisprudencia constitucional está igualmente dicho, no obstante, que esa exigencia «no implica un automatismo tal que suponga la exclusión de todo poder de apreciación por parte de los órganos administrativos a la hora de imponer una sanción concreta», de forma que, en el establecimiento de esa necesaria correspondencia entre infracción y sanción, la Ley «puede dejar márgenes más o menos amplios a la discrecionalidad administrativa». Lo que no cabe, en ningún caso, es que quede encomendada por entero a la discrecionalidad de la Administración, «ya que ello equivaldría a una simple habilitación en blanco a la Administración por norma legal vacía de contenido material propio».

Por su parte, la segunda garantía es de carácter formal y alude al rango necesario de las normas que tipifican infracciones y sanciones, en la medida que el término «legislación vigente» que utiliza el art. 25.1 CE refiere una reserva de Ley en materia sancionadora. Comoquiera, sin embargo, que en el ámbito del Derecho administrativo sancionador esa reserva no puede ser tan rigurosa como lo es en el caso de los tipos y sanciones penales stricto sensu, el Tribunal ha admitido la posibilidad de que la Ley descargue la tarea de tipificación en el escalón reglamentario, bien que con el límite infranqueable de que esa remisión termine en «una regulación independiente y no claramente 
subordinada a la Ley». Lo que significa, a fin de cuentas, que «el art. 25 CE obliga al legislador a regular por sí mismo los tipos de infracción administrativa y las sanciones correspondientes, sin que sea posible que «se puedan tipificar nuevas infracciones ni introducir nuevas sanciones o alterar el cuadro de las existentes por una norma reglamentaria cuyo contenido no esté suficientemente predeterminado o delimitado por otra con rango de Ley».

Sirviéndose de esta doctrina constitucional, y seguramente también de la opinión del Tribunal Supremo alemán (Bundesgerichtshof), que pocos días antes había censurado las citadas Guidelines por vulnerar el principio de legalidad de las sanciones (sentencia de 23 de febrero de 20135), la Audiencia Nacional concluyó a continuación, pero sin más explicaciones, que la aplicación de los criterios ideados por la citada Comunicación de la CNMC traducía, en el caso de las infracciones muy graves entonces examinado, una modificación constitucional mente prohibida del cuadro sancionador previsto en la LDC y contraria por tanto al art. 25.1 CE. Literalmente la citada SAN declaró que

[...] los criterios de la CNC, en cuanto a la aplicación de las sanciones, puede alcanzar a una graduación dentro de la previsión legal, lo que el Tribunal Constitucional denomina «cuadro de las existentes».

Interpretar los artículos 10 [de la Ley de 1989] y 63 [LDC] en el sentido de que el $10 \%$ del volumen de negocios opera exclusivamente como límite a la cuantificación de las sanciones que la CNC pueda imponer, de suerte que tal órgano administrativo es libre de aplicar cualesquiera porcentajes sobre el valor de las ventas de los bienes y servicios o volumen de negocio en relación directa o indirecta con la infracción, contradice frontalmente el principio de Lex certa y reserva legal, respecto de las sanciones administrativas que recoge el artículo 25 de la Constitución en la interpretación que de este precepto nos da el Tribunal Constitucional.

$[\ldots]$

En conclusión hemos de señalar:

a) Una interpretación del límite del 10\% conforme a la Constitución, exige entender que el mínimo de la sanción será el 0\% y el máximo el $10 \%$ debiendo graduarse la multa dentro de esta escala, según las agravantes y atenuantes concurrentes, valorando su duración y gravedad, desde la perspectiva de la escala establecida por el legislador de 2007, respecto de las infracciones leves - hasta el 1\%—, de las graves — hasta el 5\%—, y de las muy graves - hasta el $10 \%$ - Nada impide que las respectivas multas se fijen en atención a toda la escala, pero razonando en cada caso la concreta

5 Cfr. Patricia Pérez Fernández, «EI Supremo alemán se separa del Tribunal de J usticia en materia de multas», blog Derecho Mercantil, de 22 de mayo de 2013. 
gravedad en la conducta de cada infractor que justifique la fijación del concreto porcentaje.

b) Las amplias facultades que el Reglamento CEE 1/2003 otorga a la Comisión en la graduación de las sanciones no son trasladables a la CNC, de una parte, porque el Derecho europeo no se las concede, de otra parte, porque el Derecho español lo impide por rango constitucional, y, por último, porque no existe semejanza entre la naturaleza jurídica de la Comisión y de la CNC.

\section{La Sentencia del Tribunal Supremo de 29 de enero de 2015}

Esta sentencia, a la que enseguida siguieron otras con idéntico criterio (cfr., entre otras, SSAN de 7 y 8 de marzo de 2013, 10 de abril de 2013, 24 de junio de 2013, y 12 y 14 de marzo de 2014), provocó varios comentarios $^{6}$ y levantó algunas ampollas. Singularmente en la propia CNMC, que observó con preocupación cómo los Tribunales podían terminar echando por tierra el sistema que con tanta buena fe había ideado en 2009. Por eso, a la primera oportunidad que tuvo, contra la correspondiente sentencia de la Audiencia Nacional formuló recurso de casación ante el Tribunal Supremo, defendiendo su legalidad.

En su recurso la CNMC no combatió, sin embargo, y como a primera vista cabría imaginar, la infracción del principio de lex certa que le había censurado la Audiencia Nacional ${ }^{7}$. En su lugar, según testimonia la propia sentencia de casación, se limitó a defender, echando mano de la jurisprudencia comunitario-europea que antes se ha resumi do, que el indicado límite del $10 \%$ en el caso de las infracciones muy graves refería un límite externo, infranqueable en la determinación final de la sanción,

6 Cfr. C. Lillo Álvarez (2014), «La Audiencia Nacional ante las sanciones impuestas por la CNMC en aplicación de la Ley 15/2007, de defensa de la competencia», Revista de Derecho de la Competencia y la Distribución, 15, págs. 51 y sS.; M. VéLEZ FrAGA (2013), «El cálculo de las sanciones en materia de defensa de la competencia según la reciente doctrina de la Audiencia Nacional», Actualidad J urídica Uría Menéndez, 35, págs. 88 y ss.

7 Esa tacha, en los términos en que está formulada, ofrecía un flanco débil que el abogado del Estado decidió, sin embargo, no aprovechar. Pues, con la doctrina constitucional en la mano que se ha recordado en el texto y teniendo en cuenta las conclusiones de la sentencia, no es fácil ver, en efecto, en qué forma la Comunicación de la CNMC comentada vulnera efectivamente el principio de taxatividad o de lex certa de las sanciones. Entre otras razones, pero en forma concluyente, porque la exigencia de taxatividad o de lex certa se predica del legisladorlato sensu, no de la Administración. Como recuerda la STC 145/2013, de 11 de julio, resumiendo la doctrina constitucional al respecto, «el principio de taxatividad se dirige, por un lado "al legislador y al poder reglamentario", exigiéndoles el "máximo esfuerzo posible" para garantizar la seguridad jurídica [...]; afecta, por otro, a los aplicadores del Derecho administrativo sancionador [...y], se traduce, en particular, en la necesidad de que la Administración en el ejercicio de su potestad sancionadora identifique el fundamento legal de la sanción impuesta en cada resolución sancionatoria» (FJ 4). 
pero que en rigor funciona únicamente como umbral de nivelación para evitar que la multa previamente calculada siguiendo los criterios de la Comunicación arriesgue la supervivencia de la propia empresa infractora y, al cabo también, de ese modo, termine por comprometer la finalidad disuasoria que es característica de las sanciones administrativas. Pero al parecer nada o muy poco más, en efecto.

La citada sentencia del Tribunal Supremo de 29 de enero de 2015 (re curso de casación 2872/2013) es la primera de una larga serie de resoluciones (SSTS de 30 de enero, 5, 9 y 27 de febrero, 4 de mayo, 8, 17 y 22 de junio, 11, 28 y 30 de septiembre y 2 de octubre de 2015), y que niegan definitivamente por ahora la posibilidad de que CNMC mirea los criterios de la Comunicación cuando fija la cuantía de las multas que impone ${ }^{8}$.

Para terminar en esta conclusión, la sentencia comienza notando (FJ 5) que el método de cálculo defendido por la CNMC podrá acaso ser correcto si se observa desde la perspectiva del art. 23 del Reglamento 1/2003, pero no, en cambio, si se hace a la luz del art. 25.1 CE, que es la única manera correcta de hacerlo.

Al respecto, recuerda que la tipificación de las sanciones con arreglo a la fórmula elegida por el 63.1 LDC, que fija, como ya nos consta, la sanción de multa de modo abierto con arreglo a un intervalo o escala limitada en su parte superior por un determinado importe (cifrado en este caso un porcentaje del 1, 5 o 10\% del volumen de negocios total de la empresa infractora, según se trate de infracciones leves, graves o muy graves) significa, «según los criterios hermenéuticos usuales en Derecho» y certifica la preposición «hasta» que por tres veces utiliza el art. 63.1 de la LDC que,

[...] cada uno de esos tres porcentajes] marcan el máximo rigor sancionador para la sanción correspondiente a la conducta infractora que, dentro de cada categoría, tenga la mayor densidad antijurídica. Cada uno de esos

\footnotetext{
8 A propósito de esta decisiva sentencia se han publicado numerosos comentarios. Entre otros, véase J. Alfaro Águila-Real, «El límite del $10 \%$ del volumen de negocio en las multas por cártel», blog Derecho Mercantil, de 30 de enero de 2015; FRANCIOS MARCOS, «Blowinghot and cold: the last Word of the Supreme Court on setting fines for competición Law infringements in Spain», Working Paper IE Law Scholol, AJ 8-220-I, de 19 de febrero de 2015; B. LozANo CUTANDA, «El Tribunal Supremo se pronuncia sobre los criterios de cálculo de las multas de defensa de la competencia: comentario a la STS de 29 de enero de 2015», Diario La Ley, 8497, Sección Tribuna, de 10 de marzo de 2015; J. C. Laguna De PAZ, «Criterios para la fijación de las sanciones en materia de defensa de la competencia por las autoridades españolas. A propósito de la STS de 29 de enero de 2015», en La Ley Mercantil, 12, marzo 2015, págs. 84 y sS.; F. DíEz Estella y J. García-Verdugo, «Las Guidelines del Bundeskartellamt como referencia delas multas de la CNMC tras la sentencia del Tribunal Supremo de 29 de enero de 2015», en I J ornada de la Red Académica de Derecho de la Competencia, en www.osservatorioantitrust.eu; y J. ORTEGA BernaRdo, «Como agua de mayo. Comentario a la STS de 29 de enero de 2015 en su valoración de los criterios de soft law que aplica la CNC (actual CNMC)», blog Derecho Mercantil, de 27 de mayo de 2015.
} 
tres porcentajes, precisamente por su cualidad de tope o techo de la respuesta sancionadora aplicable a la infracción más reprochable de las posibles dentro de su categoría, han de servir de referencia para, a partir de ellos y hacia abajo, calcular la multa que ha de imponerse al resto de infracciones.

Hasta aquí ciertamente nada que decir. Setrata, en efecto, de una fórmula de tipificación de las sanciones bien conocida en el ordenamiento sancionador y sobre cuyo significado, por lo mismo, es muy difícil llegar a confundirse: el importe de la correspondiente multa administrativa debe moverse forzosamente dentro de los límites marcados por la ley, de modo que no puede nunca superar el respectivo límite legal máximo, so pena, en otro caso, de vulnerar el principio de legalidad del art. 25.1 CE, y que en su manifestación más genuina impide la imposición de sanciones no previstas legalmente.

Mucho más difícil resulta en cambio comprender las razones por las que el Tribunal Supremo declara que la CNMC no puede aplicar los criterios de su Comunicación, por vulnerar los principios constitucionales vinculados al ius puniendi del Estado y, de modo particular, el principio de legalidad de las sanciones ${ }^{9}$.

Formalmente, a efectos dialécticos, podría entenderlo, por supuesto, si la legalidad de la citada Comunicación hubiera sido cuestionada en el recurso contencioso considerado (recurso núm. 29/2012). Basta, sin embargo, con repasar la STS de 29 de enero de 2015, que ahora se comenta, como ya antes la dictada por la Audiencia Nacional en el citado asunto, de 24 de junio de 2013, para comprobar que el recurso contencioso entonces formulado tenía únicamente por objeto la discusión de la correspondiente sanción de la CNMC, con fundamento, en lo que ahora más importa, en su pretendida desproporción. Desde luego, en las sentencias consi deradas no hay ningún rastro de que la sociedad mercantil entonces recurrente cuestionara la legalidad de la Comunicación. Por ninguna otra razón, ni la Audiencia Nacional primero, ni el Tribunal Supremo, después, se pronuncian sobre este extremo, como en otro caso hubiera sido lógicamente obligado (art. 27 LJCA).

En estas condiciones y descartado, en consecuencia, que el recurso contencioso tuviera por objeto el control abstracto de la legalidad de la

9 Sorprendentemente, sin embargo, y en lo que he podido comprobar, prácticamente todos los autores que se han ocupado de esta sentencia coinciden en destacar su acierto en este punto. Singularmente es el caso de J. Alfaro Águila-Real, «El límite del 10\%...», cit., y F. Díez EsTELLA yJ . GarcíA-Verdugo, «Las Guidelines del Bundeskartellamt como referencia de las multas de la CNMC....», cit. Una opinión algo distinta y también más crítica es la que defiende J. Ortega Bernardo, «Como agua de mayo. Comentario a la STS de 29 de enero de 2015...», cit. 
Comunicación de la $\mathrm{CNMC}^{10}$, la cuestión debatida consistía únicamente en dilucidar si el importe de la multa considerado en el citado asunto había respetado o no el principio de proporcionalidad de las sanciones denunciado por la sociedad recurrente.

Con estos presupuestos procesales, una primera y curiosa conclusión salta inmediatamente a la vista de la sentencia: no hay en sus razonamientos ni una sola palabra sobre la concreta sanción de multa entonces recurrida ni sobre su denunciada desproporción. Lo único que consta, y en buen número además, son explicaciones acerca de la inexistencia de una regulación europea uniforme en esta materia y de las diferencias que por este motivo separan el art. 23 del Reglamento comunitario 1/2003 de los arts. 63 y 64 LDC y (FJ 6), y sobre los límites constitucionales de la colaboración reglamentaria en la determinación normativa de las sanciones (FJ 7).

A poco que se observe podrá verse que esta forma de razonar no es, en efecto, muy convincente y alerta ya sobre la debilidad de la sentencia y de todas las demás que simplemente luego la han seguido ad pedem leterem. Pues, como se ha advertido, si lo único que realmente estaba en tela de juicio en el proceso contencioso era la desproporción de la multa recurrida, es elemental entonces que esas explicaciones resultan rigurosamente incapaces de justificar su anulación por ese motivo. Sencillamente porque nada dicen sobre esa tacha.

La sentencia, en efecto, no declara que el importe de la multa recurrida sea desproporcionado, o que no haya calibrado bien las circunstancias modificativas de la responsabilidad concurrentes en ese caso ni, menos aún, que la sanción considerada supere el límite legal del $10 \%$ del art. 63.1 c) LDC previsto para corregir las infracciones muy graves. Tampoco censura que las pautas de la Comunicación se aparten o contradigan los criterios de graduación de las sanciones del art. 64 LDC. Como ni siquiera, en fin, reprocha a la resolución sancionadora de la CNMC que no motive las razones que en el supuesto considerado determinaron el importe de la multa impuesta. Lo único que afirma, y en forma tajante además, es que el citado $10 \%$ no puede ser considerado un «mero umbral de nivelación» y que el importe de la sanción no puede ser fijado

10 Una posibilidad, por lo demás, que la propia STS ni siquiera valora, al negar que la Comunicación sea en rigor manifestación de la potestad normativa, toda vez que el ordenamiento «no ha atribuido a la Comisión Nacional de Competencia potestades reglamentarias en la materia, careciendo de esta naturaleza y de carácter vinculante ad extra sus comunicaciones» (FJ 7). La Comunicación es un ejemplo más de soft law, y de los problemas teóricos que provoca este tipo de actos o instrumentos. Sobre esta cuestión, véase, por todos, D. SaRmiento (2006), «La autoridad del Derecho y la naturaleza del softlaw», Cuadernos deDerecho Público, 28, págs. 221 y ss.; y (2008), EI Soft Law Administrativo, Civitas, Madrid. 
«con arreglo a las pautas de la Comunicación». O, como poco después subrayará el propio Tribunal Supremo a propósito de este mismo núcleo de problemas, el importe de la multa calculado por la CNMC no es efectivamente el correcto, «pues ha sido fijado a partir de un método de cálculo [que no es] conforme a Derecho» (STS de 22 de junio de 2015).

De la mano de estas declaraciones de la sentencia bien se ve enseguida que, en el criterio del Tribunal Supremo, la nulidad de la sanción se funda, no en su desproporción, sino en el método empleado por la CNMC para calcular su importe. Lo que significa que el defecto no está en el acto sancionador, sino en su motivación ${ }^{11}$.

Si estas observaciones son correctas no hay duda entonces que el razonamiento de la sentencia pierde pie y se tambalea. Pues, teniendo en cuenta la motivación que usualmente consta en las resoluciones sancionadoras de la CNMC, concluir que ese tipo de explicaciones no sirve para justificar el importe de la multa en cada caso considerado es desde luego bastante discutible. Entre otras razones, vista la tradicional tolerancia con la que la jurisprudencia observa de ordinario la exigencia de motivación de la extensión o el quantum de las sanciones ${ }^{12}$.

De hecho, conforme testimonia esa misma jurisprudencia, tengo casi por seguro que el Tribunal Supremo no hubiera anulado la multa si en esa ocasión la CNMC no hubiera razonado como lo hizo y hubiera justificado el importe de la sanción sin acudir a la Comunicación o, incluso, no hubiera dicho rigurosamente nada al respecto. La jurisprudencia, tanto contenciosa como constitucional ${ }^{13}$, prueba muy bien, en efecto, cómo en supuestos de este tipo el simple hecho de que en la resolución sancionadora

11 Esta precisión no es para nada inocua o simplemente de detalle, sino realmente decisiva y de consecuencias nada despreciables. Por lo pronto, obliga a trasladar la cuestión desde el derecho a la legalidad sancionadora del art. 25.1 CE (en el que, en su caso pero todo lo más y por conexión, funciona constitucionalmente el principio de proporcionalidad), al del derecho a obtener una resolución fundada en Derecho del art. 24.1 CE. Cfr., al respecto, Ios AATC 130/2008, de 26 de mayo, y 331/2008, de 27 de octubre.

12 Según es consolidada doctrina constitucional, el control ex art. 24.1 CE de la extensión de la sanciones se contraer a examinar si el correspondiente quantum «resulta o no manifiestamente irrazonable o arbitrario, siendo el arbitrio del que disponga en cada caso la Administración dentro de los márgenes previstos por la norma sancionadora la medida de la motivación constitucionalmente exigible (por todas, STC 28/2007, de 12 de febrero, FJ 4). Una declaración que en ocasiones tiene incluso mayor vigor. Como es el caso de la STC 25/2011, de 14 de marzo, en la que el Tribunal subraya que «cuando los datos básicos del proceso de individualización de la pena puedan inferirse de los hechos probados, no resultan constitucionalmente exigibles ulteriores razonamientos que los traduzcan en una cuantificación de pena exacta, dada la imposibilidad de sentar un criterio que mida lo que, de suyo, no es susceptible de medición». En el mismo sentido cfr., entre otras, SSTC 47/1998, de 2 de marzo; 136/2003, de 30 de junio; y 98/2005, de 18 de abril.

13 Cfr., entre otras muchas, SSTC 40/2008, 212/2009 y 192/2011. Del lado de la jurisprudencia contenciosa, véase, igualmente por todas, SSTS de 30 de junio de 2006, de 27 de mayo y 8 de noviembre de 2008, y de 2 de junio de 2010. 
no consten anotados los criterios de graduación utilizados, ni explicadas las razones que justifican el quantum o alcance de la correspondiente sanción, no es motivo suficiente para acordar su nulidad, siempre y cuando del conjunto del expediente o de los hechos declarados probados puedan deducirse razonablemente las razones que lo justifican.

En este contexto jurisprudencial, la decisión del Tribunal Supremo que se comenta no es, en efecto, nada fácil de comprender y tiene a primera vista una apariencia bastante inquietante. Pues significa algo así como que por la boca muere el pez o, peor aún, que el detalle en las explicaciones de la CNMC sobre las razones que justifican el quantum de la multa estuviera reñido con la exigencia de motivación de las resoluciones sancionadoras.

\section{Observaciones finales}

I mágenes aparte y comoquiera que esta última es una conclusión imposible de compartir jurídicamente es preciso rebuscar algo más en los razonamientos de la sentencia para poder encontrar alguna explicación añadida que justifique su conclusión.

Desde esta perspectiva, admito que es posible ver que, antes que su defectuosa motivación, lo que en rigor reprocha el Tribunal Supremo a la resolución de la CNMC es que la aplicación de los criterios de la Comunicación pueda concluir en sus dos primeras fases en un importe de la sanción superior al $10 \%$ del VNT, por más que luego, en la tercera fase, ese importe acabe rebajándose hasta ajustarse al indicado porcentaje máximo. De modo que lo verdaderamente decisivo son las operaciones y los cálculos intermedios y no, en cambio, el resultado final del proceso de determinación del quantum de la multa.

Con algo más de rigor, y apurando este razonamiento, incluso es posible advertir también que lo que verdaderamente despunta en el reproche de la STS es el riesgo de que el denominado importebásico de las sanciones, corregido con el correspondiente coeficiente de ajuste, arroje un saldo superior al límite de la correspondiente franja o tramo sancionador y termine, por esa vía, por reducir a simple agua de borrajas la escala de graduación prevista por la LDC, igualando a la postre la sanción con su respectivo límite máximo ${ }^{14}$. Por decirlo de otro modo, y según

14 La siguiente declaración de la sentencia así parece sugerirlo: «el método implica, en una buena parte de los casos, establecer un sesgo al alza de los importes de las multas no adaptado a las exigencias del principio de proporcionalidad, para aplicar ulteriormente sólo a modo de correctivo el porcentaje del diez por ciento del volumen de negocios» (FJ 5). 
esta otra interpretación, para el Tribunal Supremo, allí donde la Ley ha previsto una escala o franja sancionadora, la Administración no puede luego ignorarla superando en sus cálculos el límite legal de la máxima sanción para después simplemente ajustar el importe final a ese límite. Sencillamente porque, por esa vía, la Comunicación acaba por neutralizar la aplicación de los criterios legales de graduación de la sanción del art. 64 LDC y, en especial, de las circunstancias atenuantes ${ }^{15}$.

De todas formas, y sea o no finalmente este el verdadero leitmotiv de la sentencia comentada, me parece en cualquier caso que sus declaraciones no permiten ver que la única forma correcta de determinar (y de recalcular) el importe de la multa sea la que, en atención de la calificación de la infracción en una de las tres categorías (leve, grave o muy grave), arranca del respectivo umbral (el 0 , el 1 o el 5\% del volumen de negocios total) para ascender en la correspondiente escala porcentual y hasta el límite respectivo (el 1, el 5 o el 10\%) en función de los concretos criterios de graduación que la LDC ha previsto, de modo que la multa ha de medirse siempre en un determinado porcentaje del VTN, reservando además el máximo para las infracciones más groseras y antijurídicas. Ni menos aún, pero por lo mismo, permite afirmar que la utilización de cualquier otra fórmula de cálculo y, en particular, cualquier precisión ad hoc sobre el modo de calcular el importe de la multa resulte incompatible con los principios que ordenan el ejercicio de la potestad sancionadora de la Administración.

Entre otras razones, porque la LDC no ordena que la multa correspondiente a cada infracción deba ser siempre y forzosamente la expresión de un determinado porcentaje del VNT. Sólo impone que la multa no supere el respectivo límite máximo porcentual, que es algo bien distinto. De modo que, según yo lo veo, el porcentaje sobre el VNT que fija el art. 63.1 LDC determina simplemente el saldo máximo de la multa que puede ser impuesta en cada caso, pero no que ése sea precisamente el único criterio o la medida a utilizar en todo caso para calcularla.

En resumidas cuentas, pues, y a salvo del reproche antes observado ${ }^{16}$, no es fácil ver en la sentencia comentada cuál es la razón que impi-

15 Este es un riesgo particularmente apreciable en las empresas monoproducto y que por lo mismo concentran su actividad en el mercado afectado por la infracción, que sirve precisamente de base para el cálculo del denominado importe básico. Al respecto, aunque sumariamente, vid., J. C. LAGUnA DE PAZ, «Criterios para la fijación de las sanciones....», cit., p. 89; y P. PÉREZ FERNÁNDEZ, «EI Supremo alemán se separa del Tribunal de J usticia en materia de multas», cit.

${ }^{16}$ Esa posible justificación de la sentencia acerca de que la Comunicación incorpora un inaceptable «sesgo al alza de los importes delas multas» (y que constituye, por las razones antes apuntadas en el texto, la única puerta abierta con relativo rigor a la conclusión de la sentencia) prescinde no obstante de las concretas circunstancias del caso considerado, sacrificándolas en el altar de una doctrina o reproche general que, sin embargo, como también se ha notado, no 
de que la CNMC determine el importe de la multa a imponer con arreglo a las pautas de cálculo que ha ideado ni, menos aún, para concluir sencillamente que las mismas no son conforme a Derecho. Debe insistirse, lo serán finalmente si: i) el método de la Comunicación (soft law) pugna efectivamente con los criterios legales de graduación (hard law) previstos por la LDC ${ }^{17}$; ii) su aplicación determina la imposición de una multa por importe superior al máximo legal (expresado en el porcentaje del VNT); o en fin, iii) si el importe de la multa impuesta en cada caso con arreglo a las pautas de la Comunicación no se ajusta a las circunstancias modificativas concurrentes en el correspondiente asunto y no guarda, por consiguiente, la obligada proporción con la gravedad de la infracción detectada.

Pero sobre esta necesaria comprobación la sentencia no dice rigurosamente nada o muy poco, como ya nos consta.

cuadra muy bien con el desmentido de la sentencia que niega a radiceel carácter normativo de la Comunicación. Por lo demás, en esta última advertencia están comprometidos interrogantes dogmáticos de primer orden, y todavía pendientes de resolver entre nosotros. Singularmente apunta, de un lado, a la cuestión del valor normativo y la eficacia (ad intra y/o ad extra) de este tipo de actos o instrumentos de soft law y su control judicial. Y, de otro, al no menos decisivo asunto de determinar su grado de integración en la norma de conducta de la Administración y, en especial, en la norma de control judicial de la actividad discrecional de la Administración. Sobre estas cuestiones, y aparte de las obras citadas en la nota 10, recientemente también, J. Ma Rodríguez De SAnTiago, «La fuerza del Derecho débil» blog almacendederecho.org, de 2 de junio de 2015; y más ampliamente, «Normas de conducta y normas de control. Un estudio metodológico sobre la discrecionalidad planificadora, la ponderación y su control judicial», InDret, 1/2015.

17 Al respecto, vid., por ejemplo, la STC 91/2009, de 20 de abril (FJ 7), que censura la determinación judicial de una pena de multa acordada con arreglo a unos criterios de graduación que, aunque acaso razonables, son, sin embargo, distintos del único expresa y deliberadamente previsto por el Código Penal para graduar la pena correspondiente al delito entonces considerado. Por este motivo y con fundamento en el deber de motivación de las sentencias a que obliga el derecho a la tutela judicial efectiva (art. 24.1 CE), el Tribunal concluye que «la elección de dichos criterios en lugar del legalmente establecido no puede considerarse fundada en Derecho». 